\title{
Crooked strategy implementation: covert tactics fill the gaps
}

Marius Pretorius

An ancient Chinese proverb states that: "If you stand straight, you don't have to fear a crooked shadow". In the world of business strategy this might translate into: "if you have a strategy, beware of its crooked implementation". Of course, we know it is disastrous if strategy is not executed (no shadow?). Poor or non-execution are one of the main reasons for strategy failure.

Consultants often hold strategic planning workshops proposing the next best fad as "strategic" tool, but still, we know and see on a daily basis that often these fads, tools and strategies, and especially those associated with strategy implementation, falter more often than they succeed. It remains a consistent problem that their execution rarely achieves momentum. Our research originated in the non-execution (non-implementation) problem widely reported in theory and in practice where strategic management is pursued.

\section{Exploring the non-implementation problem}

Implementation matters (Pustkowski, Scott \& Tesvic (2014) and as a result the implementation gap has been researched widely. Non-implementation has been blamed on organisational hypocrisy (Fenton, \& Langley, 2011). It has been used to describe this situation that organisations regularly face. The concept is one of discordance (inconsistency) between what the strategy purports to bring about and the actions that practitioners take in reality. It describes the gap between what is said and what is done.

Reasons for this hypocrisy have been sought in "disconnected talk" and decisions originating from ideologies attempting to serve or respond to different stakeholders. It is especially relevant in government, political organisations, layered businesses, organisations facing sustainability compliance and even regular corporate businesses with multiple divisions, where boards and managements formulate strategies which lower level management and individuals are supposed to 1

Draft paper 2015 
implement. While many solutions (communication, alignment, balanced scorecard, etc) are proposed to cover the gap, few appear effective as the body of research into the problem continues to grow.

Further, formal strategy statements often contain phrases like "cutting edge", "stakeholder value," "leaders in service or innovation" and other generic rhetoric peppered with catch phrases, leaving the audience (implementers) blank and unable to translate the strategy to their own jobs. We use "audience" with reason, as audiences seldom become part of the action. They observe at a distance and applaud if prompted to do so. They are merely "silent observers" of an often poor and ineffective message.

In practice, it appears is as if there is an unseen force keeping the formulated strategy in organisations from reaching the implementers. Additionally, it often seems that those tasked with implementation do not really believe in the strategy (there is no performance consensus) and they pursue their own "strategic" activities that keep the organisation afloat. (See case in point 1.)

To address these problems of poor communication, ineffective message and misalignment, managers (and leaders) typically set goals (now called "strategic goals") and install scorecard alignments in collaborative workshops. If these don't bring the desired results, management introduces "new values" in the (usually unsuccessful) hope of changing the culture. Finally, they bring in more measurements. Still, success remains elusive. The question that arises is whether the proclaimed strategy is the real strategy or do other "strategies" infiltrate and later dominate the proclaimed strategy. The problem is therefore that strategy is not embedded in the implementation structures of the organisation, including employees and resource allocation and support.

\section{What is the real strategy, then?}

"This organisation still exists despite top management" is the statement that triggered this research leading to covert tactics as a concept while facilitating a recent consulting assignment. The organization has formal strategies but these 2

Draft paper 2015 
appear not to be a real focus. Rather there are other things happening in the organization. This initiated my drive to take a fresh look and try to better understand non-implementation and determine if there are other issues (dressed as strategies) that we may not be aware of as strategists and managers.

Insight eventually came after informal, and later formal, conversations with individuals from various organisations, after which a pattern emerged. The concept proposed in this paper is that of "covert tactics". Once identified, a reflection was undertaken where I evaluated my own "covert tactics" (through applying autoethnographic reflection), realising their existence, pertinence and nature in my own context.

\section{Covert tactics matters a great deal in strategy implementation}

I then embarked on exploratory research of 13 subjects over two companies, including individuals with autonomy over decision making about strategy-making in practice. A forthcoming article reports the detailed results to the academic community. The purpose of this particular paper is to share the conceptual findings with the community of business managers and strategy practitioners, who are often faced with non-implementation problems in practice.

This article tries to answer three questions:

- Can the concept of covert tactics be confirmed? If so, what is it?

- What are the antecedents and consequences of these covert tactics? And finally

- How can the consequences be addressed?

The research led to confirming the concept of "covert tactics" and suggests ways for management to address the phenomenon.

The major contribution of this article is to assist managers, consultants and support practitioners in addressing covert tactics. I simplify the response to the potential existence of covert tactics. I proceed with a description of the research design and then explain the phenomenon of covert tactics with its determinants. Two short examples are then presented as illustrations followed by a discussion and call for 3

Draft paper 2015 
further research.

\section{The research process}

Facing the implementation gap in strategy consulting and reading the literature about it, I wanted to pursue non-standard alternatives. Informal conversations and interviews were undertaken. Then, combining the literature reports with my many years of critiquing strategies as a consultant, I developed a theory of covert tactics, stumbled on during a consulting assignment. Thereafter 13 semi-structured conversations were conducted to investigate its existence and gain deeper understanding about the characteristics and associated liabilities of covert tactics. During various conversations, I applied devil's advocacy (Schwenk, 1984: Lunenburg, 2012) by challenging the subjects on issues that arose during the conversations. Data saturation was achieved before interview number nine but I continued as the phenomenon is currently unknown and I did not want to risk the potential for missing a potential unique outlier element.

Data was exposed to several rounds of analytic process iterations with the main aim of improved sense-making about the proposed phenomenon. The interpretations were subject to the biases of the researcher, including many strategy analyses during consulting and business turnarounds.

After defining the concepts, I reflected on my own micro situation at my institution. Being a senior academic with some freedom to pursue my targets, I had to acknowledge the existence of covert tactics in my own micro situation. I could identify two clear covert tactics that I pursued once I understood the phenomenon and being willing to entertain the existence thereof.

\section{The proposed phenomenon: covert tactics}

Strategy execution in practice often suffers from what can be termed the "covert tactics" followed by individuals in organisations. Being covert suggest they are unspoken and may mimic the formal strategy - like a shadow (but often crooked depending on the surface it is projected upon). A covert tactic is never documented, rarely defined, seldom mentioned, but is regularly pursued by individuals (rarely in formal teams). Few managers know about the existence of

4

Draft paper 2015 
covert tactics, as they are too busy pursuing the formal strategy goals and associated scorecards whereby they pursue implementation.

So the formal strategy is publicly advocated, while the covert tactic is what happens in the daily micro practices of individuals. Covert tactics are characterised by being informal, as they originate in the individual's mind; secondly, covert tactics are uncoordinated; thirdly, covert tactics happen in response to micro situations of the individuals, fourthly they originate from information asymmetry and, finally, covert tactics appear not to be deliberately designed to oppose the formal strategy. Let us look at each characteristic individually.

Firstly, being informal makes covert tactics hard to detect and deal with, as managers (being outsiders) are unaware of their existence. Individuals often cannot describe them precisely as they have not been formalised. Alternatively, individuals may choose not to speak about them. Covert tactics are subject to individual perceptions of the formal strategy, but are mainly driven by what individuals see as good for "themselves" and not so much for the organisation. Typically subjects told me that "I do it although there is no agreement or policy, because apologising is easier than obtaining permission anyway" or "top management doesn't know what happens on the ground, so I do what I think is right". This suggests individuals are often willing to risk censure. The informal nature of these covert tactics suggests that there is little or no consensus with the formal strategy. Occasionally covert tactics may be framed in the words of the formal strategy.

Secondly, their being uncoordinated suggests that there may be more than one covert tactic within individual, teams or units. Actually there can be as many such strategies as there are employees. One individual can also have more than one covert tactic (I identified two). My observation is that this practice is more visible at senior staff level. Individuals act in their own way, based on what they judge is relevant for their situation. In doing this, they actually show the initiative which is a sought after commodity when there is a search for management talent.

Disillusionment with higher-level management [in]competence is a strong driver that often underlies the development of these personal strategies (see case-in-point One).

5

Draft paper 2015 
Case-in-point One

Hypocrisy leading to covert tactics

$\mathrm{XYZ}$ is an organisation with 4000-plus employees operating in an education space comparable to a typical tertiary institution. The organization employs specialist academics led by management teams in departments of 20-50 people grouped into larger faculties (180-350 people), serving different knowledge sectors. For years, teaching has formed the main income stream of XYZ. Recently, due to a changing funding model countrywide, research outputs have become the ultimate output identified by the top management. This is also true for all competitor organisations, technicons, business schools and universities, even internationally.

Industry-wide, competitor organisations have responded differently in order to retain their expertise. Varying their compensation models, altering their modus operandi to include positions such as "research professors" working from home and more, institutions have started to differentiate themselves while all are pursuing the research output drive. The macro environment of the tertiary education industry has experienced turbulence.

During my initial investigations, I encountered several department heads who could not articulate what the strategy of their organisation was. Few could verbalise its specificity and repeated vague phrases from the vision statement. This status was repeatedly confirmed at lower levels in the organisation despite regular strategy sessions at various levels, where few could explain or be motivated by either the current or the newly adopted value proposition. During interviews (formal and informal), and after I asked for individual stories within units, I realized that the formal, intended strategy (driven top down) had not penetrated to lower levels. This led me to ask individuals "what does one do within this vague formal strategy?" The responses led to the understanding of the covert tactics. These strategies are the initiatives taken in response to the changing environment with the resources available to pursue some personal advantage. Subject's statements included the following to show their perception of the hypocrisy and inconsistency:

6

Draft paper 2015 
- Top management is clueless, as they have no idea what business looks like on the ground.

- Where are the resources to pursue the new goals; how serious can management be?

- I must do this, but they measure that, so what am I to do?

- They can't replace me, so they can't fire me. I am building my CV.

- Top management lives on a different planet. Reality requires me to do the right thing (this sometimes appears true when management does not want to "hear" inputs and insights from staff).

Once I understood the context, exploring their coping strategies led me to the concept of "covert tactics".

Thirdly, covert tactics function in micro situations. Micro situations refer to the portion of the (direct) environment that individuals feel that they have control over. Micro situations are the silos in which people work where they focus on themselves. People do things to improve their situation. Almost by definition people with a micro focus are not working for the benefit of the organisation at large. These micro situations determine whether people convert from being an audience to become participants. Often individuals are shown the bigger picture and even applaud the formal strategy, but at the coalface they only participate in their own micro situation. However, they adapt their actions only to the micro situation that may lead to less synergy, information withholding and resource bottlenecks. In micro situations people focus on themselves ("How can I get more?") or their teams, or their departments. Often people do things that seem beneficial at the lower level but destroy value from the whole. This includes fighting each other and competing with each other for resources and power. Significant things cannot happen in micro situations, people are just too busy maximising the parts.

Fourthly, covert tactics originate and thrive on information asymmetry. Asymmetry of information is the situation where two economic agents in a transaction have different levels/amounts of relevant information. Asymmetry may allow the agent with more information to practice opportunistic behaviour. (Besley 1995, p.29). In a recent case, a new appointment was made and as the appointee arrived, she was 7

Draft paper 2015 
informed of the closure of the division. Neither the HR and operations managers were informed of this.

Finally, covert tactics are not deliberately intended to oppose the formal strategy, thus making it difficult to contain. While it is possible, malice does not drive covert tactics to develop.

\section{What are the consequences of covert tactics?}

Since covert tactics develop in micro situations, they are less detectable, probably because they take up such a small percentage of management attention compared to that applied to the formal strategy. Unless there is congruence in the covert tactics of several individuals simultaneously, when it becomes a macro situation, covert tactics remain relatively undetectable. However, and probably most important of all, the consequences of covert tactics may be significant relative to its visibility. Such consequences may include any one or several of the following:

- A widening gap in the execution of the formal strategy by implementers which reiterates the problem this research seeks to address.

- Resistance to change / alignment associated with the deliberate strategies of the organisation.

- Derailment of the formal strategy when insufficient participation is found by the implementers of the strategy and they remain audience.

- Potential abuse by powerful individuals to gain personal benefit.

- Managers unable to lead as they fail to share the vision and integrate for generating critical mass as described by Pretorius (2009:39).

Thus, the research seems to show that even if management has a formal strategy, it is often the covert tactics that govern [non]implementation or are responsible for the lack of implementation. Our interest now turns to addressing covert tactics by managers.

\section{What actions can be used to counter covert tactics?}

Typically, a response to this question starts by pointing towards the need for more 8

Draft paper 2015 
leadership than management and other "dead horses" of business consulting. Not so. If leadership or management techniques (fads) were part of the answer, this paper would make no real contribution and would only continue to advance consulting's often mysterious contributions and abuse of the terminology, adding to the mountain of published irrelevance. To call on leadership, on the other hand, appears rather to grab for the last straw. To "motivate" employees to pursue the organisation goals have so far proven to be of little consequence to addressing covert tactics.

Conventional thinking then suggests that what must be done at this point is to close the gap between the formal and the covert tactics. This cannot happen at board level, nor can it be formally driven and dictated from the manager's office through the standard presentations, emails, workshops and meetings. Yes, to close the gap, the responsibility belongs to management - that is indisputable: to establish what the covert tactics are before the closing process can be pursued. But here is the first problem: people (employees) do not share covert tactics with people they don't trust (management), especially those who are perceived to be the origin of the problem in the first place.

Rosabeth Moss Kanter tweeted (Comments (46) | June 11, 2012) that "if you don't like how things are going, tell a different story". The new story replaces the old. Innovative thinking, therefore, suggests the complete removal of the covert tactics, thereby eliminating the gap completely. How can this be achieved? I propose the pursuit of strategy embedding. When the strategy becomes embedded in the micro situation, free choice of association by individuals with the formal strategy becomes easier. The real question then becomes how to increase embeddedness similar to what Pretorius \& Le Roux (2012) describe for sustainability embeddedness. The answer, I propose, can be found in changing the strategy message, referring to the core message that conveys the strategy. This message has the power to change the micro situation for the individual. Embeddedness of the strategy will only be achieved when those who hear (the audience) become participants. Covert tactics are a sign of non-participation and thus an unsuccessful strategy message.

To become embedded in the micro environment of the employee, the strategy 9

Draft paper 2015 
message needs to be simple, uncomplicated and memorable, removed from all clutter. Malcolm Gladwell refers to such a message as "sticky". This requires each employee to understand the business and even more so, their role in it. This depends on a high level of understanding by all staff. Warren Buffet once said he does not invest in internet ventures as he does not understand their business: what they sell or how they make their money - both applicable points in this context of the formal strategy implementation (see case in point 2).

Organisations need strategy messages that all members can link to their personal micro situations and jobs. Not rocket science, one would say. No, but very difficult to achieve in practice. Long, detailed and comprehensive visions, missions and strategic plans often prove to be useless. It is the same with business plans in general. It is the thinking and process of creating the plan that is more important not the plan itself. If the plan or strategy is longer than a page, it is doubtful whether it will be read by anyone outside management. Not being read equals no understanding, equals no buy-in, nor any potential for stay-in by individual and then covert tactics develop. Strategy embeddedness increases with the simplicity of the message. The message requires the disciplined pursuit of less fluff. Case-inpoint Two explains the concept well.

\section{Case-in-point Two}

The strategy message as solution

A senior executive of a local banking group confirmed to me that they have no formal "vision, mission and strategy statements". What they do have is a clear strategy message embedded with all staff as well as customers. Their positioning is clear and everyone understands the business model and participates in pursuing the core message of simplicity, accessibility and affordability in their micro environments. No audience exists. Everyone is a participant (messenger) who talks and acts in accordance with the story, their story. Everyone makes decisions because they can.

It seems amazingly simple when they do it. It shows in their products, market

10

Draft paper 2015 
segments pursued, facilities, resources, staff, equipment, systems, and appointment criteria - everywhere, as demonstrated by the branch manager's "office" right in the middle of the branch, consisting of an affordable desk and computer screen and within five meters of the door for customer access. Their tagline reads: "Simplicity is the ultimate sophistication". There is no place for any covert tactics to develop, no need to, as the strategy message is clear.

This view of covert tactics is not yet well received by bureaucratic boards and high level management and biased leaders. Often management thinks the bigger the words, the better the strategy. Progressive thinkers, however, start to believe me only when we expose the "ugly truth" (Kim \& Maughbourne, 2005) of discordance to them during strategy critique workshops. The change of perspective requires challenging one's own thinking. Overcoming bias contamination is key to finding the strategy message. A strategy is embedded only when the audience becomes participants. When they participate, they don't pursue covert tactics; there is no need for them to do so. The message must seamlessly enable their micro situation to be part of the bigger situation.

To conclude, once understood, covert tactics are often more real than formal strategies unless the message of the formal strategy is clear. Covert tactics are the responses of employees to organisational hypocrisy (disparity between talking and doing) and they follow the disconnectedness resulting from management being unable to get the message across. The effort to identify covert tactics is ineffective, so the opportunity for their development should rather be replaced (eliminated) completely. This requires a clear strategy message.

A contrary view, offered by one subject, might be that covert tactics are where emerging strategies originate. What if one wanted covert tactics to be part of the innovative processes in the organisation? To answer that, further research would be required, as it would depend on how innovative the organisational culture is.

In the eighties, the concept of management-by-walking-around (MBWA) was popular but seemed to fade as other fads replaced it. It appears that MBWA 11 Draft paper 2015 
addressed real goal pursuance at the micro situation level. This research may call for a relook at the concept as a tool for aligning employee thinking within their micro situations to align with the strategy.

\section{Study limitations and future research}

Limitations of one study serve as challenges for future research. The search for covert tactics depends heavily on researcher interpretations as subjects were not necessarily knowledgeable about it as strategy per se. Despite this, an interesting picture was discovered, illustrating the existence of such tactics. No empirical data is presented in this paper and the study was deductive in nature, investigating the practical problems associated with the limited implementation problem that persists. Future research into the practices that can be used to address covert tactics should be promoted.

\section{Acknowledgements}

The contributions of the subjects are acknowledged with gratitude.

\section{About the author}

Dr. Marius Pretorius is a Professor in Strategy, Leadership and Turnaround in the Department of Business Management, University of Pretoria, South Africa. He consults with ventures on strategy issues with a focus on those that experience distress and seek turnaround. He has also published articles in the field of entrepreneurship.

\section{References:}

Kim, W.C. \& Mauborgne, R. 2005. Value innovation: a leap into the blue ocean. Journal of Business Strategy, 26(4): 22-28.

Fenton, C. \& Langley, A. 2011. Strategy as practice and the narrative turn. Organisational studies 32(9): 1171-1196.

12

Draft paper 2015 
Lunenburg, F. C. 2012. Devils's advocacy and dialectical enquiry. International Journal of Scholarly Academic Intelectual Diversity, 14(1):1-9.

Pretorius, M. 2009. "Leadership liabilities of newly appointed managers - arrive prepared." Strategy \& Leadership. Vol. 37 (4) 37-42.

Pustkowski, R., Scott, J. \& Tesvic, J. 2014. Why implementation matters. McKinsey\&Company. August.

Schwenk, C.R. 1984. Devil's Advocacy in Managerial Decision-making. Journal of Management Studies, 21(2): 153-168.

Moss Kanter, R. 2012. If You Don't Like Your Future, Rewrite Your Past. [Online] 24th June 2012. Available from: Harvard Business Review.org. http://blogs.hbr.org/2012/06/if-you-dont-like-your-future-r/. [Accessed: 09th September 2014].

13

Draft paper 2015 